\title{
LA RESTAURACIÓN DE MONUMENTOS A LAS PUERTAS DEL SIGLO XXI
}

\author{
(THE RESTORATION OF MONUMENTS AT THE DOORS OF THE XXI CENTURY)
}

Antoni González Moreno-Navarro, arquitecto. Jefe del Servicio del Patrimonio Arquitectónico de la Diputación de Barcelona. ESPAÑA

\section{RESUMEN}

Este texto corresponde a la conferencia leida el 23 de mayo de 1991 en el Instituto de Ciencias de la Construcción Eduardo Torroja de Madrid, dentro de la programación de los Seminarios Torroja sobre "Tecnología de la construcción y sus materiales". El autor propone una nueva lectura de la historia de la restauración, especialmente del desbarajuste vivido en España en los últimos 15 años, comprobando cómo en cada época se han tenido en cuenta las dos facetas del monumento: su carácter de documento histórico y de objeto arquitectónico vivo. Esa lectura es imprescindible ya que la necesaria redefinición de la disciplina - al mismo tiempo cientifica y creativa- que ahora que entra en su tercera centuria, ha de partir del análisis objetivo de sus fines y sus medios, fundamentado en la consideración equilibrada de ese doble aspecto del monumento y de la precisión del concepto de su "autenticidad".

\section{SUMMARY}

The text corresponds to the conference pronounced in May 1991 at the Eduardo Torroja Institute of Construction Sciences in Madrid as part of the programme of the "Torroja Seminars on Construction Technology and Materials". The author proposes a new interpretation of the history of restoration, especially of the disequilibrium that Spain has undergone in the last fifteen years, establishing how in each period to two facets of the monument -is character as an historical document and as a living architectural

monument- were considered. This interpretation is essential given that the necessary redefinition on the discipline - both scientific and creative - that is now entering is third century, must be based on an objective analysis of its ends and means, founded on the balanced consideration and accuracy of the concept of its "authenticity".
Un día oi en el televisor (confieso que la televisión la oigo más que escucharla y, por supuesto, mucho más que mirarla) que alguien hablaba de restauración. Y aunque nunca sabes si al amparo de esta mágica palabra

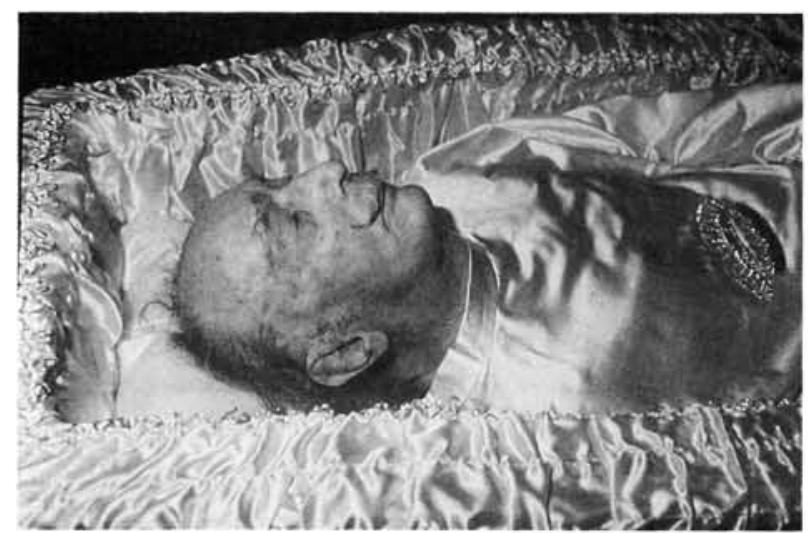

1.- La restauración de Salvador Dali, una lección (foto: gentileza de Interviu). se referirán a la ensalada fria de pasta fresca de Rosa Grau, nuestra gran cocinera, o al trabajo de un odontólogo o incluso a la labor de un interventor dispuesto a redimir una partida presupuestaria olvidada - que hoy en día a todo se le llama restauración-, lo cierto es que llevado de una cierta deformación profesional, presté atención a la pantalla.

Efectivamente no se trataba de una restauración monumental lo que alli se comentaba. No era un arquitecto, ni un historiador, quien era entrevistado: era un cirujano, pero fue una auténtica restauración lo que explicó. La restauración -el propio doctor la bautizó asi-del cadáver de nuestro gran pintor Salvador Dalí, definitivamente fallecido pocos días antes en su Empordà natal. Por fortuna, el cirujano no entró en detalles sobre las técnicas empleadas en su labor restauratoria, pero expuso con claridad los criterios de su intervención. 
“Por causa de la enfermedad", dijo, "Dali llegó a tener un aspecto lamentable, a convertirse en una ruina. Como teniamos que exponerlo en la capilla ardiente, ante el público, ante la televisión, pensé que habia de de. volverle una imagen adecuada. Evidentemente no podia retornarle a su juventud, con sus bigotes erguidos y su sonrisa de sorna; no por motivos técnicos" (recuerdo que dijo el médico que sí hubiera podido hacerlo) "sino por motivos de credibilidad".

"Nadie hubiera aceptado aquella imagen del genio; así que" - dijo el médico- "le devolvi la imagen que te. nía antes de la enfermedad, la que la gente podía recordar con ternura"...; la imagen de un Dali mayor pero no viejo, o viejo pero no destruido.

La reconstrucción era pues posible y legítima. El límite era sólo cuestión de técnica, de rigor científico y, sobre todo, de intencionalidad (sólo la voluntad de mostrar al difunto justificaba una manipulación que en otro caso hubiera sido gratuita).

¿No ocurre acaso lo mismo, pensé, en la restauración monumental?

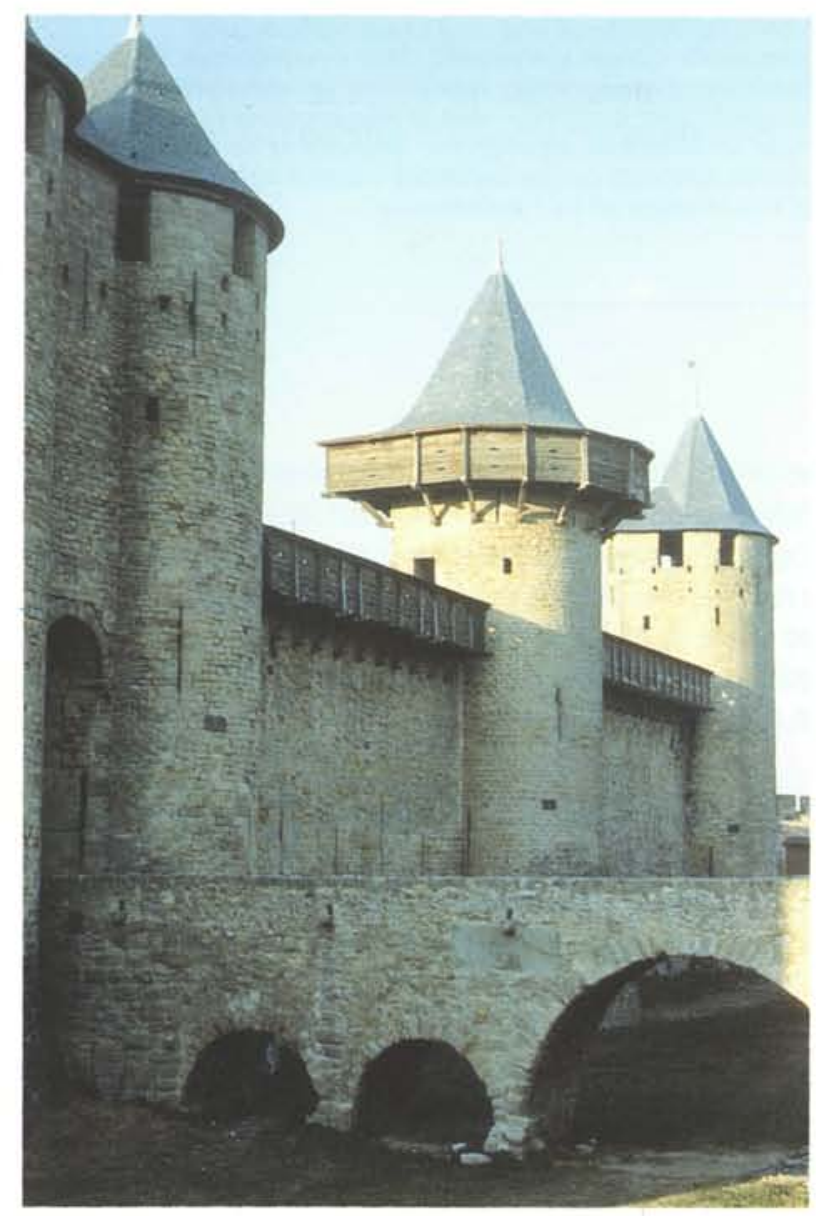

2.- La ciudadela de Carcasona, una obra admirable de Viollet le Duc. Foto Arxiu GMN.
Dos años después, otra referencia periodistica, esta vez en la prensa, relacionada también con una actuación profesional ajena a la arquitectura me sumió en una reflexión similar. (1)

Según aquella noticia, Shigeaki Saegusa, un polifacético compositor japonés de 48 años, habia completado, por encargo del Museo de Mozart, una sinfonia que Mozart inició en 1778, y se desconoce -decía el diario- la razón por la que no pudo acabarla. Habia llegado a escribir 51 notas y a esbozar otras 134 sobre un total de 457 de que constaba el proyecto. En total cinco minutos.

La nueva sinfonia, que será estrenada el 5 de diciembre de 1991 en Salzsburgo, para celebrar el 200 aniversario de la muerte del músico austríaco, tiene una duración de 20 minutos, y cuatro tiempos. Arranca con el que llegó a escribir Mozart. En el segundo, Saegusa ha orquestado los fragmentos que esbozó el músico austríaco, conservando la melodia del primer tiempo. El tercero es una composición del autor japonés pero concebida "al estilo de Mozart", y el cuarto es una oda carente de armonia y de contrapunto, conforme marcan los cánones orientales, sin más referencia a Mozart que el hecho de tratarse de un homenaje que le rinde el compositor nipón.

Saegusa, como Hernán Ruiz (compárese la nueva sinfonia con la catedral de Córdoba), ha planteado el diálogo con lo viejo sin renunciar a la manera de entender su propio arte. Una manera de acercarse un creador de hoy a la mentalidad de un creador de ayer para, "juntos", producir una obra que pueda ser transmitida al mañana. Cuantas veces, pensé yo leyendo el diario, poco más que eso es la restauración monumental.

Pero, ¿es ése un pensamiento generalizado entre las gentes de la restauración? La legitimidad de la reconstrucción del monumento - - , en el caso de estar inacabado, de completarlo- no es más que una de las múltiples dudas que acostumbran a asaltar a quienes se estrenan en el mundo de la restauración arquitectónica, e incluso a los que llevamos años en ello. Unas preguntas, habituales también entre profanos, que se hacen en un contexto más amplio: la licitud de "manipular" los restos monumentales heredados, no sólo cuando nos ha llegado una ruina o una obra inacabada, sino también cuando las alteraciones que el monumento tuvo a lo largo de su historia no permiten com. prender su mensaje. Unas preguntas que tienen casi tantas respuestas como personas las puedan formuIar. ¿Es esa dispersión de respuestas aceptable como normal?

\section{El concepto de restauración}

Ciertamente, para quien esté alejado de este mundo complejo de la restauración monumental puede resul- 
tar incomprensible que aún hoy, cuando estamos a punto de meternos en el tercer milenio de la Era, y en el tercer siglo de la restauración como disciplina explícita, ésta se debata continuamente entre dudas que afectan no tan sólo a su metodología, sino a lo más profundo de su concepto.

La restauración, ¿es el cómo conservar - conforme a unas reglas preestablecidas - una arquitectura que, por merecer protección, ha detenido su evolución?; ¿es una manera determinada - también con sus reglas de entender cómo actuar sobre una arquitectura en irremediable evolución permanente? ¿o quizás tan sólo se trata del conjunto heterogéneo de actitudes y acciones - sin regla alguna - que tienen como protagonista la arquitectura pre-existente?

Sólo el análisis detenido de la evolución del concepto y la práctica de la restauración, nos puede facilitar el acercamiento a la respuesta; una respuesta imprescindible para definir lo que puede ser la restauración a partir de hoy, en los umbrales del nuevo siglo.

Parece claro que en el origen de esta diversidad de práxis y teorias, y de la endémica discusión, no está, como a veces se plantea, una discrepancia ideológica -o incluso de ética personal o social - respecto a la actuación sobre el patrimonio que hemos heredado; ni la mayor o menor pericia o genialidad de los arquitectos en el ejercicio reflexivo de la disciplina de la composición arquitectónica, como algún autor ha insinuado (2). Menos aún, ha sido una simple cuestión de gustos o de estilos en el ejercicio de la arquitectura.

A mi juicio, esa diversidad de pensamientos y acciones ha reflejado, por encima de todo, la distinta valoración que en las diferentes épocas y lugares, se ha hecho de los dos aspectos básicos del monumento: su condición de documento (el monumento como testimonio informativo y conmemorativo de la historia o del arte del pasado) y de objeto arquitectónico (que como tal, además de sus valores documentales como testimonio de la arquitectura histórica, mantiene vigentes sus valores de uso, estéticos o emblemáticos) (3). Ha sido en función de cómo la sociedad, los teóricos o los profesionales han valorado relativamente esos parámetros, como se ha planteado la actuación sobre el monumento.

Por ello, hoy - vigente ahora como hace doscientos años esta doble consideración del monumento- conviene releer la historia que nos han explicado y sacar conclusiones para replantear la restauración.

Cuando en el siglo XVI el arquitecto Hernán Ruiz, el Joven, remozó el viejo alminar almohade de la mezquita de Sevilla - que se convirtió asi en la Giralda, la torre de la catedral -, como cuando unos años antes su padre, Hernán Ruiz, el Viejo, inició la transformación de la mezquita de Córdoba en catedral cristiana, que veiamos antes, actuaron como era habitual entonces, aprovechando la obra vieja en buen estado y concibien. do la nueva según el gusto de la época, sin pretender imitar lo antiguo.

La actitud de los Hernán Ruiz supuso, por otra parte, una efectiva protección patrimonial. Fue su sensibilidad al conservar lo viejo más allá de lo estrictamente utilitario y armonizar sabiamente lo nuevo, la que faci. litó la transmisión a futuras generaciones de dos monumentos que en otras manos quizás hubieran sucumbido para siempre. Es muy posible, no obstante, que los tracistas no tuvieran conciencia de proteger aquellas viejas arquitecturas, menos aún de restaurarlas.

Habían de transcurrir un par de siglos aún para que naciera la restauración. Porque aunque hallemos ejemplos aislados de protección en las más variadas épocas y culturas, no es hasta finales del siglo XVIII cuando la sociedad toma conciencia y hace de la protec. ción del patrimonio histórico un objetivo colectivo explícito. Los peligros (guerras, revueltas sociales, reformas urbanas, la codicia de coleccionistas y anticuarios) que amenazaban en Europa un patrimonio revalorizado por la cultura ilustrada, serian los causantes de esa nueva mentalidad protectora, desconocida como tal hasta entonces.

Uno de los efectos que produjo esa nueva mentalidad, además de las acciones de catalogación y salvaguarda en las que pronto se empeñarán los poderes públicos, fue el cambio de actitud de los arquitectos al actuar sobre edificios antiguos.

A partir del siglo XIX -en aras a la formación en aquella época, según Brandi (4), de la "conciencia histórica", del monumento- ya no parece posible, o cuanto menos plausible, la actuación de los Hernán Ruiz comentada; ni tan sólo quizás el leve sacrificio de una bóveda gótica, como hiciera en 1721 Narciso Tomé para implantar en el deambulatorio de la catedral de Toledo el famoso "transparente" barroco.

La nueva fachada ochocentista de la catedral gótica de Barcelona puede ser un ejemplo de ese cambio de actitud (un cambio que, desgraciadamente, impidió que Barcelona pudiera contar hoy con una maravillosa e irrepetible catedral gótico-modernista, lo que pudiera haber ocurrido si, por ejemplo, con una actitud a lo Hernán Ruiz hubiera sido Gaudi el encargado de acabarla).

Definitivamente alterada la actitud de los arquitectos en su trabajo sobre la arquitectura existente, para conservarla o para transformarla, pronto cuajará con perfiles propios la nueva disciplina, la restauración, actividad que en la práctica se manifestó desde un principio de muy diversas maneras, evolucionando en medio de una permanente polémica, que como os decía tie- 


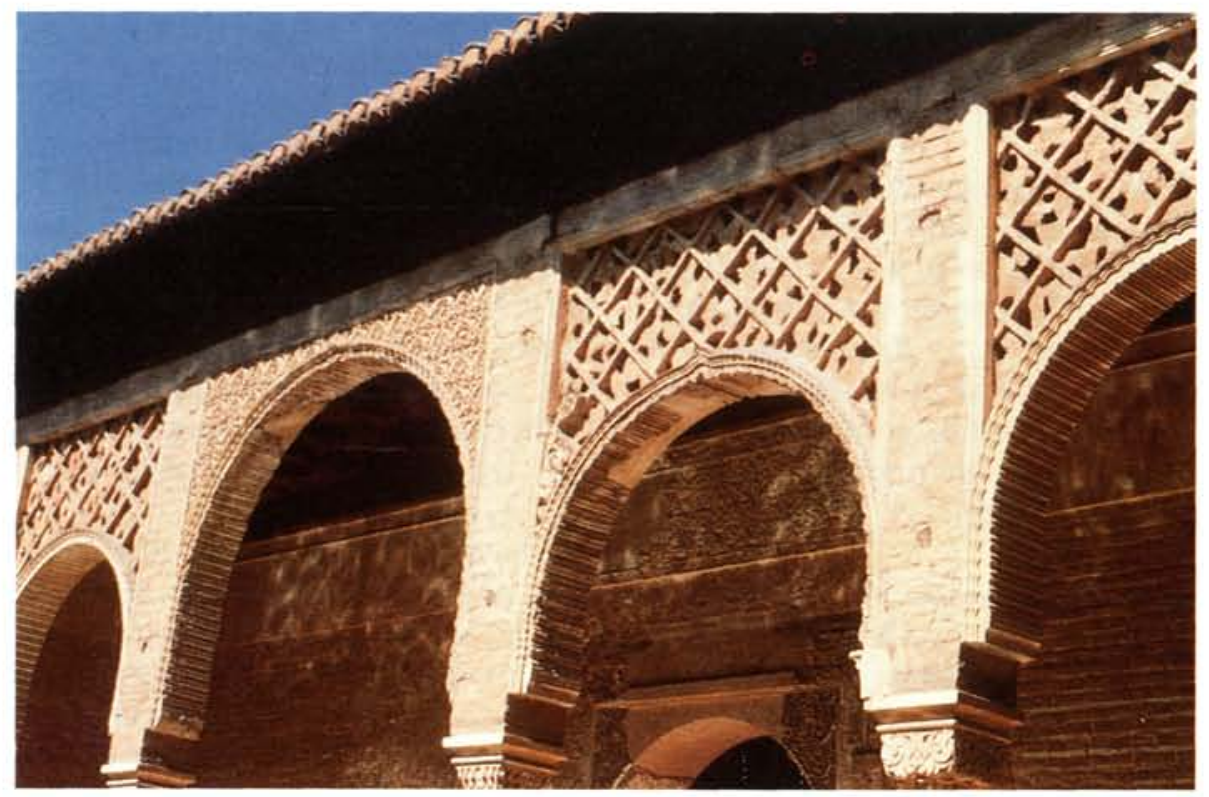

3.- La reintegración de la imagen en la Alhambra, obra de Leopoldo Torres Balbás. (Foto: Arxiu GMN).

nen a mi juicio su causa en esa diversa consideración de la esencia del monumento.

Efectivamente, la polémica suscitada ya en el siglo XIX -y que va a estar presente hasta hoy en cualquier discusión sobre restauración-, polarizada entre el optimismo creativo de Viollet le Duc ("hay que recuperar el esplendor inicial del monumento", dijo, "o el que pu. do tener...") y las propuestas pesimistas, casi eutaná. sicas, de John Ruskin (que llegó a decir, "Ios monu. mentos no se han de tocar, mejor dejarlos morir"), tiene su origen en la diversa consideración de los aspec. tos esenciales del monumento (documental y arquitectónico) a los que me vengo refiriendo.

Para Viollet le Duc, como para quienes nos sentimos identificados con su mensaje, la capacidad motivadora del monumento radica en su condición arquitectónica, tanto por constituir un "documento arquitectónico", como por ser "arquitectura viva" capaz aún de asumir nuevas funciones para la colectividad; en el otro extremo, Ruskin valora más del monumento su mensaje testimonial y nostálgico como arquitectura muerta (¡Cuántas veces comparó el escritor ìnglés al monumento con un cadáver por enterrar o un moribundo por consolar!).

\section{El monumento como documento}

Las doctrinas o corrientes de pensamiento que se basan en una valoración prioritaria del monumento como testimonio de la historia o el arte del pasado, han sido durante estos dos siglos las que más han influido en la definición de los comportamientos que se consideraban más correctos a priori, lo que ha conducido a la disciplina de la restauración por caminos, casi todos insuficientes para responder a la complejidad del monumento e incluso han inducido a su negación.

La elocuente frase de John Ruskin: "Cuidad los monumentos y no necesitaréis restaurarlos" (5), una frase brillante, en parte cierta, pero capciosa, ya que olvida que restaurar puede obedecer a la necesidad de adaptar el monumento a otros usos, resume suficientemente el pensamiento del escritor inglés, reconocido paladin de esa negación. El conde de Santibañez del Río, uno de los mejores representantes españoles de esta actitud antirrestauradora - confundida a veces con una visión de raiz estética derivada del romanticismo-, nos confirma que es una actitud que nace de la consideración documental del monumento: "un documento - dijo- que hay que mantener libre de toda alteración como testigo de tiempos pretéritos".

http://informesdelaconstruccion.revistas.csic.es 
Contemplando también al monumento sólo como documento, pero lejos de la pasividad que predicó Ruskin, ha existido desde siempre una corriente que ha defendido como camino válido su estricta conservación, lo que entendemos por consolidación. Giuseppe Veladier, autor a principios del siglo XIX de la restitución analógica del arco de Tito de Roma, y de creativas soluciones para detener el deterioro del Colosseo; Camilo Boito, propagador de la llamada restauración cientifica -adjetivo peligroso por excluyente-, o Cesare Brandi, formulador hace unas pocas décadas de una escrupulosa teoría de la restauración (6), son algunos de los definidores de esta actitud que ha aportado páginas brillantes a la historia de esta disciplina pero que ha pecado también de olvidar la esencia arquitectónica del monumento.

Otras actitudes, tampoco alejadas del concepto de estricta conservación o consolidación del documento nos emocionan más, no en balde incorporan soluciones creativas, más propias de la disciplina de la arquitectura. Es el caso de la recuperación de la forma y el espacio aunque no de la materia, que propuso en la primera mitad de nuestro siglo don Leopoldo Torres Balbás, quizás el más sensible de los restauradores españoles, con la reintegración de la imagen ensayada por él en la restauración de la Alhambra granadina. Recuperar claustros perdidos mediante setos que hacen las veces de muros o suplir delicados e irrepetibles trabajos de yeso desaparecidos mediante cascotes de ladrillo que vistos de lejos apenas si denotan su condición, fue una imaginativa y creativa consolidación del monumento-documento, y un paso adelante en su consideración no únicamente como documento histórico sino también como "documento arquitectónico".

Las fervorosas reconstrucciones a las que se dieron con tanto entusiasmo nuestros antepasados, también parten de la valoración de ese aspecto documental del monumento, el mismo que preside la actitud consolidadora. Remover fábricas, eliminar añadidos, rehacer partes desaparecidas, "mejorar" en definitiva el monumento heredado, no deja de suponer una fe ciega en su capacidad documental y testimonial.

La reconstrucción, como la consolidación (utilizando estas palabras, aun a riesgo de esquematismos) han sido, pues, conductas cuantitativamente muy diferentes en cuanto al grado de intervención en el monumento, pero conceptualmente más próximas de lo que parece.

La diferencia esencial entre ambas, normalmente, ha radicado en la distinta valoración que hacian del monumento, un patrimonio bien distinto, incluso desde un punto de vista documental de otras creaciones artisticas. Recuperar el espacio y la forma como elementos esenciales que son de la arquitectura - que no pueden ser comprendidos tras la simple consolidación de los fragmentos-, es una valoración más objetiva de la esencia documental del monumento como documento arquitectónico. Sepamos pues leer lo que de positivo ha tenido en la historia de la restauración, la tantas veces e injustamente denostada reconstrucción monumental.

Sin embargo, donde los rasgos esenciales de la valoración del monumento como documento arquitectónico (el análisis genuinamente arquitectónico -de su espacio, de su composición, de su uso-; la recuperación de su autenticidad, la aportación creativa en los nuevos diseños), se hallan magistralmente presentes en una de las intervenciones más sugerentes realizadas en un monumento en el siglo XX: la restauración de la catedral de Mallorca por Antoni Gaudí.

Este templo gótico erigido por los catalanes tras la conquista de Mallorca por el rey Jaume I, construido entre 1230 y 1601, está considerado como el más espacioso de los realizados en piedra. La altura y la amplitud de sus naves, los casi 22 metros de sus columnas (las más esbeltas de todas las catedrales góticas), los efectos de la luz sobre las desnudas fábricas, hacen de su interior uno de los espacios más sugestivos de nuestro arte.

En 1904, el obispo mallorquin Pere Joan Campins encargó a Antoni Gaudí que pusiera orden en aquel espacio, enturbiado por las aportaciones de los últimos siglos e inadaptado a la liturgia vigente. La obra del arquitecto, que levantó una polvareda que aún hoy no ha escampado, fue perfectamente definida por él mismo: "No se trata de una reforma, sino de una restauración, y no en el sentido restringido de rehacer elementos de un determinado estilo o época, sacrificando las otras épocas, sino" - añadió el arquitecto en una preciosa definición del concepto de restauración - "en el sentido de volver las cosas a su lugary a su verdadera función" (7).

Fruto del análisis arquitectónico del monumento, "volvieron a su lugar y su función", el presbiterio, la sede episcopal, los púlpitos y algunos retablos; la búsqueda de la autenticidad, llevó a desmontar y trasladar el coro que trastocaba el espacio original; el genio creativo de Gaudi produjo el altar, el nuevo baldaquino y lampadario, las nuevas vidrieras, la decoración de los muros, la nueva y atractiva iluminación.

Gaudí, a propósito de su intervención en la Seo mallorquina, dijo: "Hagamos arquitectura sin arqueología (8): ante todo están las relaciones entre las cosas, en una situación predispuesta; por esto no debemos copiar las formas, sino estar en condición de producirlas dentro de un determinado carácter, poseyendo su espiritu" (9). Gaudí, quizás sin proponérselo y "desde fuera" de la disciplina, había dado una de las lecciones más brillantes de la historia de la restauración. 


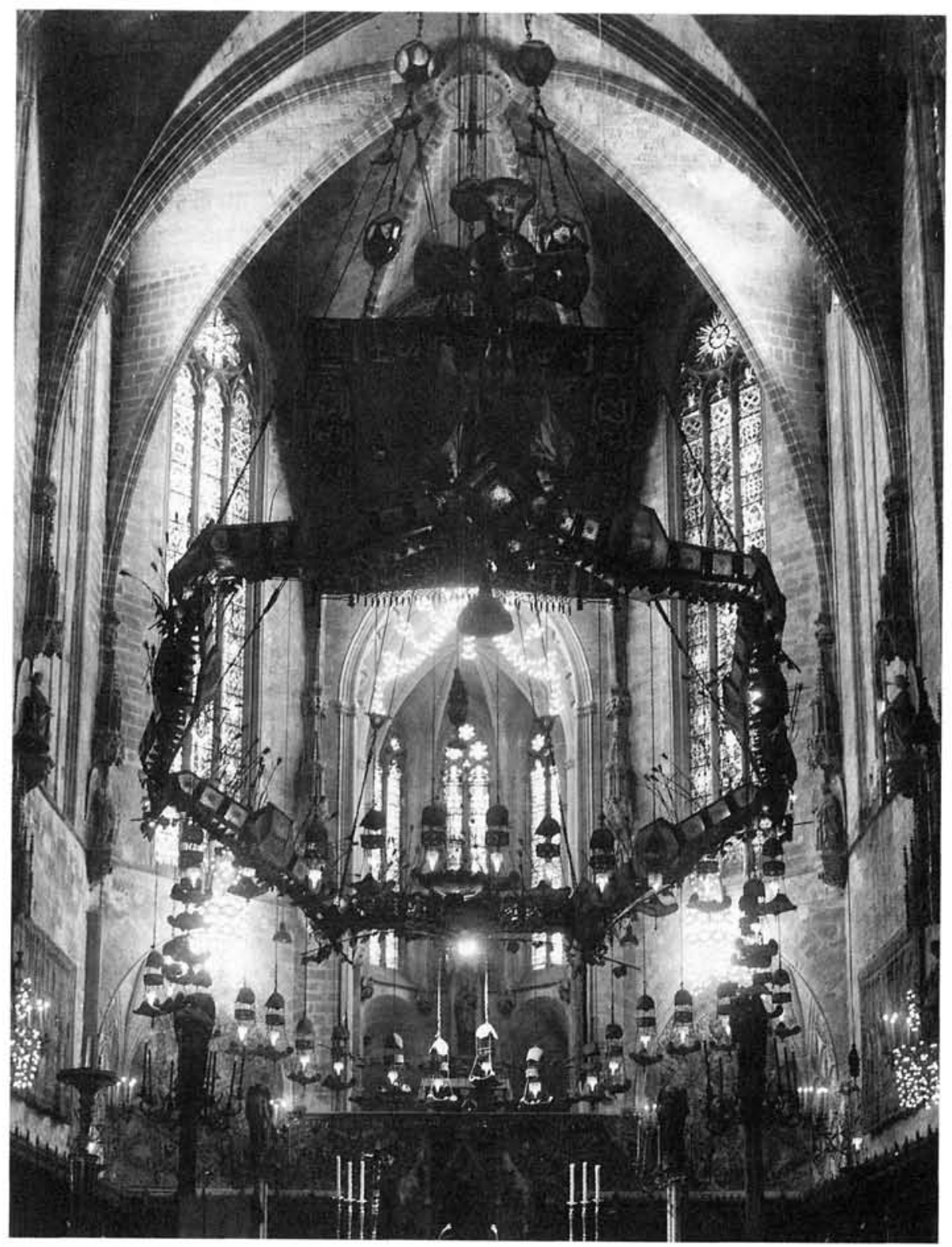

4.-Presbiterio de la catedral de Palma de Mallorca, de Antoni Gaudi. Una obra maestra de la intervención en la arquitectura histórica. (Foto: F. Català Roca). 


\section{El monumento como arquitectura}

Son relativamente pocos los monumentos que tienen tal trascendencia cultural como documentos de la historia que justifique que la sociedad haya hecho todo lo necesario para mantenerlos en pie a pesar de haber perdido su vigencia como arquitectura. La voluntad de conservación de una gran mayoría de nuestros monumentos ha ido unida a su uso (un uso "práctico" - el original, u otro nuevo- o un uso "emblemático", como símbolo de la identidad o las ilusiones, esperanzas, sentimientos o afanes de una comunidad), ha ido pareja, por tanto, a su carácter de objeto arquitectónico vivo.

Es quizás en el tratamiento de estos monumentos donde mejor se comprende y justifica la otra gran corriente de la restauración, la llamada precisamente restau. radora, considerada - no siempre con precisión - heredera de las teorias de Viollet le Duc. Los arquitectos fieles a la corriente restauradora son, sin duda, los que mejor han sabido asumir las aspiraciones y necesidades colectivas respecto de los monumentos, potenciando en ellos el papel emblemático y significativo que les corresponde.

Fue el caso del excelente arquitecto catalán Elias Rogent reconstruyendo a finales del siglo pasado Santa Maria de Ripoll asumiendo un sentimiento patriótico colectivo que encontró en el amor a los monumentos su mejor medio de expresión. Quizás el monasterio que vemos hoy tiene poco que ver con el que fundara Wifredo, el Belloso: es la servidumbre que el rigor cientifico debió pagar en aquellas épocas para satisfacer esas legitimas aspiraciones colectivas.

El hecho de que muchas reconstrucciones reflejen la torpeza de sus fantasiosos autores, ha provocado un rechazo indiscriminado de esta mentalidad, muy a menudo injustificado: ¿No fue acaso una excelente aportación a la cualificación de un paisaje urbano, la reconstrucción - tantas veces criticada- del Alcázar de Segovia? ¿No son las murallas de Ávila otro ejemplar tributo de la restauración a la renovación urbana de una ciudad? ¿No fue socialmente más rentable la reconstrucción del monasterio de Poblet (con la vuelta de los monjes y su actividad cultural) que la hipotética consolidación de sus bellas pero inútiles ruinas? ¿No es en este sentido mucho más comprensible socialmente la restauración llevada a cabo en el monasterio ca-

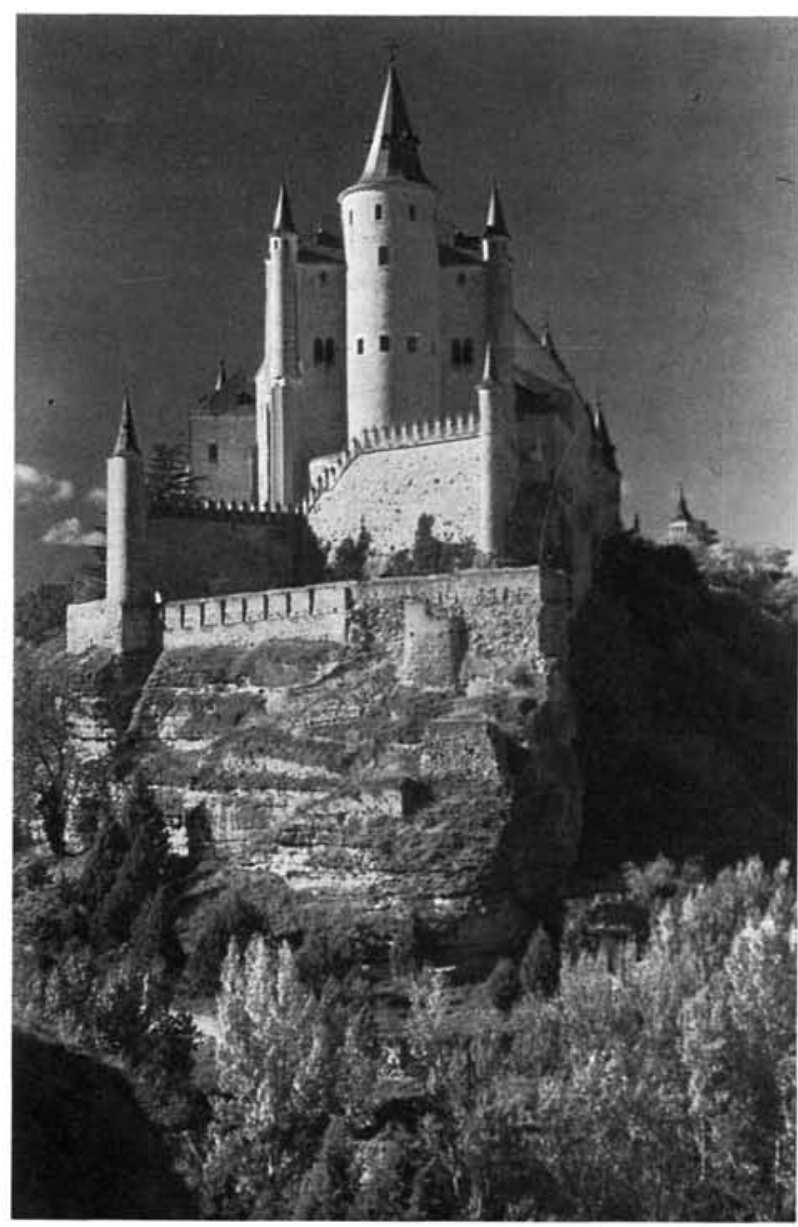

5.- La bella y discutida restauración del alcázar de Sego. via. (Foto: Arxiu GMN).

talán que la que actualmente se hace en otro monasterio cisterciense, el de Carracedo, todo y tener la obra de Pérez Arroyo y Susana Mora aspectos brillantísimos en lo conceptual y en lo formal?

En todos los casos de reconstrucción citados pueden justificarse muchos de los reparos, históricos o estilisticos, de los especialistas. Pero, ¿no se compensan los posibles errores con la eficaz satisfacción de los legítimos objetivos colectivos que presidieron esas obras?

El arquitecto catalán Jeroni Martorell, fue quizás quien más hizo en España para superar las divergencias derivadas de la diferente valoración de los aspectos científicos, sentimentales y arquitectónicos del monumento. Defensor de la consolidación, se inició en la disciplina como director del primer servicio de monumentos español, el Servei de Catalogació i Conservació de Monuments, creado en 1914 por la Diputación de Barcelona y, bien pronto, su bagage doctrinal se fue enriqueciendo y matizando con el realismo al que obliga la función pública hasta comprender que la restauración debia ampliar sus puntos de mira.

http://informesdelaconstruccion.revistas.csic.es 


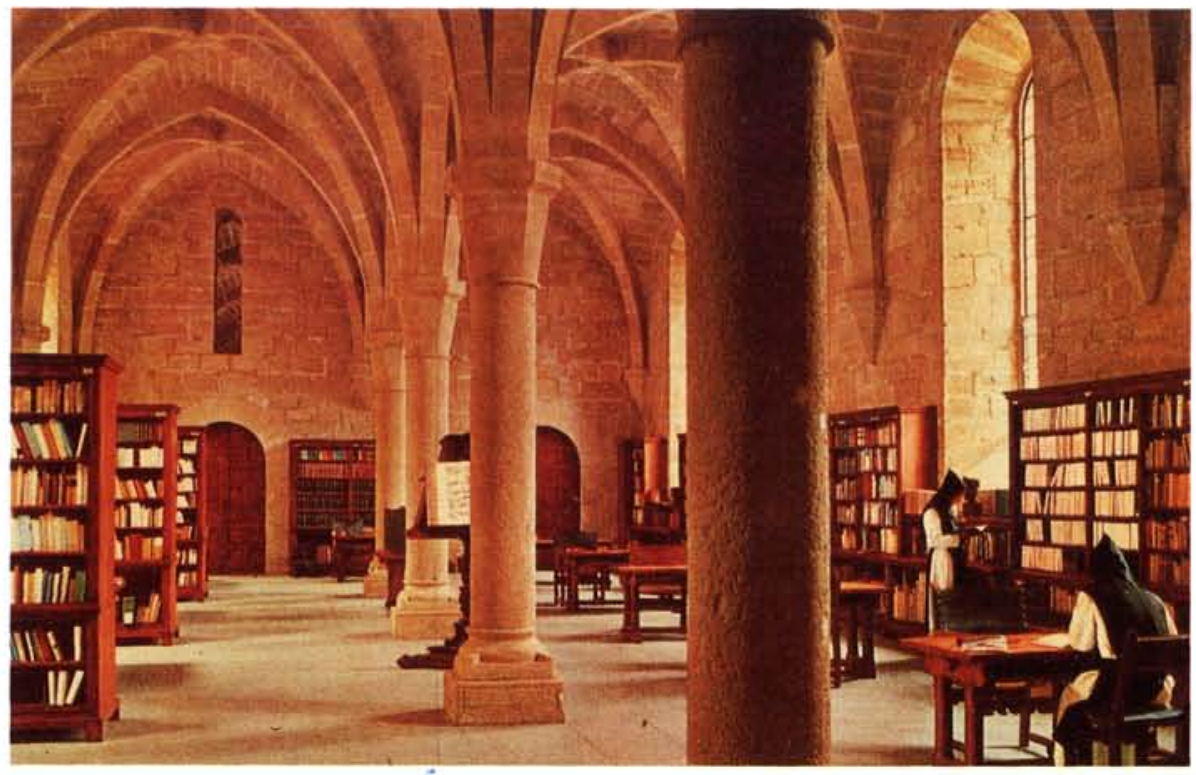

6.-Restauración del monasterio cisterciense de Poblet (Tarragona). (Foto: Arxiu GMN)

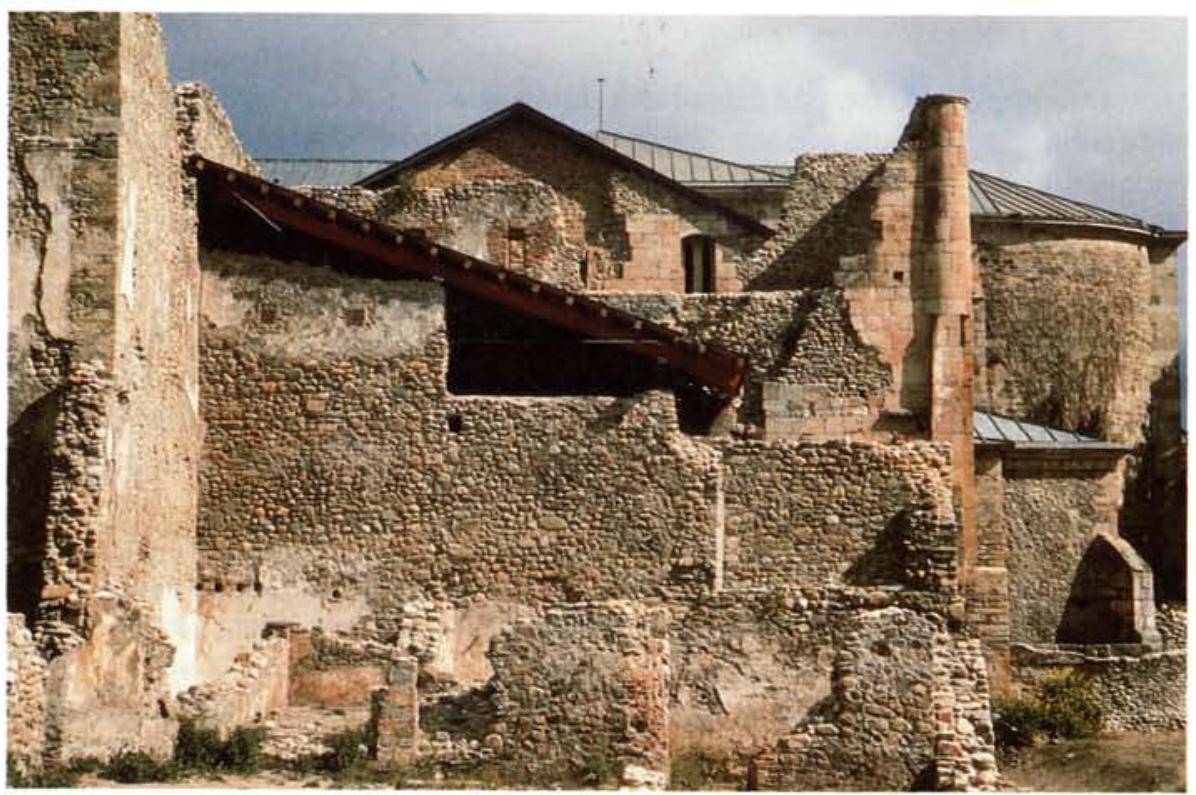

7.-Restauración del monasterio cisterciense de Carracedo (León). Salvador Pérez Arroyo, arquitecto y Susana Mora, arquitecta. (Foto: Arxiu GMN). 


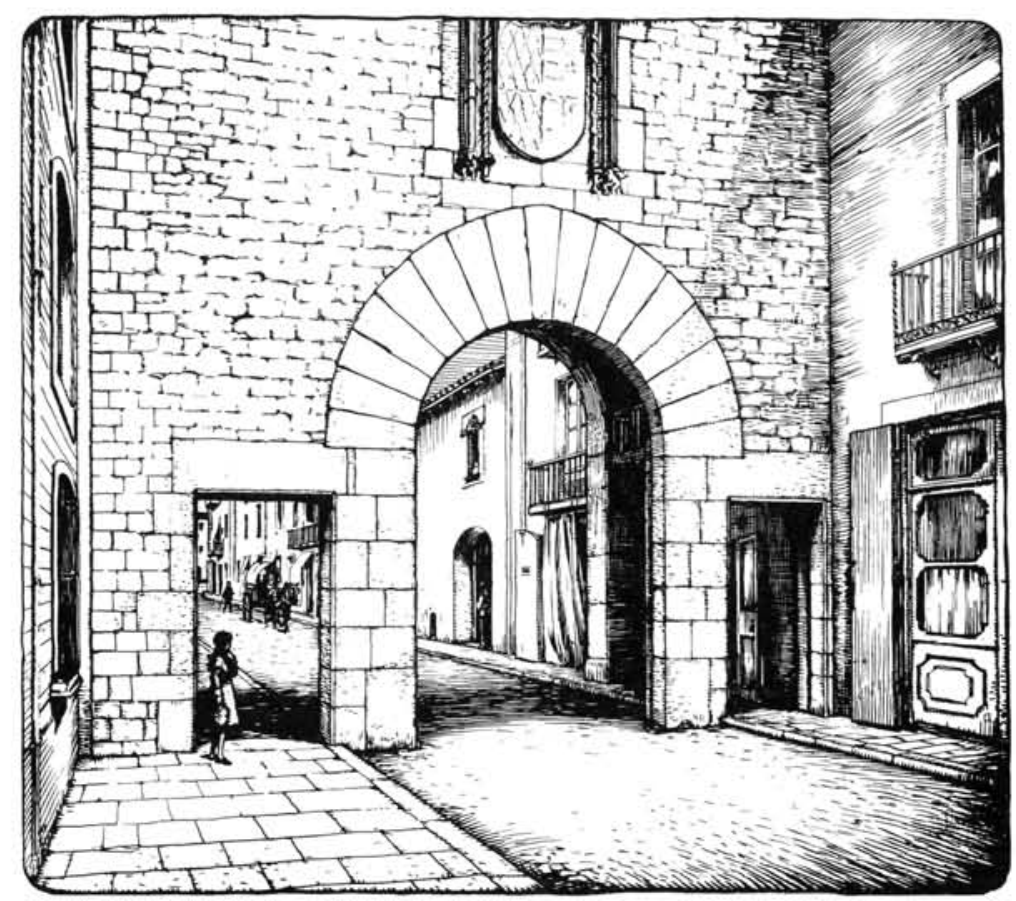

8.-El portal de Centelles, obra restaurada por Jeroni Martorell. Compatibilizar el uso con la conservación (dibujo gentileza de la Diputación de Barcelona).

Martorell evidenció la necesidad de usar los monumentos $-y$ de respetar las legitimas exigencias de los usuarios - y el papel de los monumentos en la definición de las ciudades y la ordenación del territorio; propugnó, en consecuencia, una restauración comprometida en la defensa de los valores documentales del monumento, pero también con sus valores genuinamente arquitectónicos, incluso urbanísticos (10). Su restauración del portal de la muralla de la villa de Centelles, fue un excelente ejemplo de cómo compaginar el uso práctico del monumento sin detrimento de sus valores históricos.

Si unos años antes fue Antoni Gaudi, en la citada reforma de la catedral de Mallorca, quien nos recordaba que la intervención en los monumentos puede y debe seguir siendo siempre un acto creativo (como lo fueron las actuaciones de los Hernán Ruiz en Sevilla y Córdoba), Jeroni Martorell nos enseñó que los monumen. tos, además de documentos históricos que deben ser respetados como tales, son $-y$ no pueden dejar de serlo- arquitectura viva al servicio de la gente.

\section{El desbarajuste español}

En esta lectura intencionada de la historia de la restauración interesa ahora detenernos en el último tercio de nuestro siglo, parco en teorias globales y testigo de menos proclamas doctrinales que los lustros anteriores, pero que ha vivido auténticas convulsiones en las práxis restauratorias.

La reconstrucción de Europa después de la segunda guerra mundial que dio paso a las más variadas conductas, el debate arquitectónico fruto del ocaso del movimiento moderno y la consiguiente crisis de creatividad, la revalorización del papel de la historia, las crisis económicas, la aparición y desarrollo de las técnicas analíticas y terapéuticas, han traqueteado el de por si complejo mundo de la restauración, radicalizando posturas, aumentando más que disminuyendo el pesado lastre con que la disciplina camina hacia su tercera centuria. 
En España, donde la reflexión teórica paralela a la reconstrucción europea nos pilló en el adormecido panorama cultural de una inacabable postguerra civil - adomecido panorama que permitió que se enquis. tara una concepción retórica de la más ramplona ver. sión de la reconstrucción monumental-, el interés colectivo por la vieja arquitectura no se despertó hasta el final de la década de los setenta. En ese momento - coincidente con la democratización de las adminis. traciones locales - la cantidad de déficits de equipamientos heredados, y de monumentos infrautilizados, incubaron una eclosión reautilizadora que puso patas arriba la inmensa mayoria de un patrimonio hasta entonces olvidado.

La escasez de profesionales de la arquitectura con una suficiente reflexión sobre la actuación en los monumentos y los tejidos históricos, producto del olvido de la cultura de la restauración como consecuencia de tantos años de aislamiento; la precariedad de los instrumentos de control y asesoramiento en manos públicas, incluso la desorientación de la nueva administración democrática al distribuir los recursos (aspectos no mejorados con la descentralización del Estado autonómico), provocaron un caos en la teoria y la práctica de la

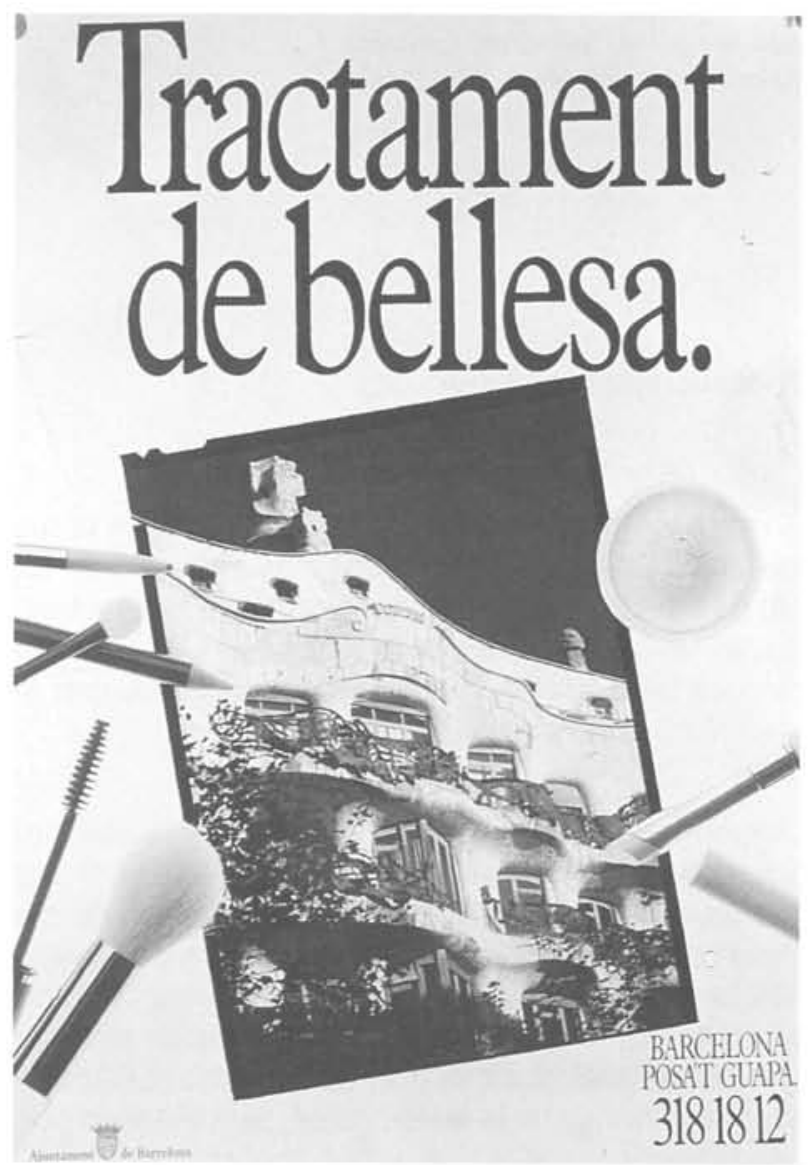

9.- Confundir la restauración con la cosmética, una situa. ción de alto riesgo para el patrimonio. restauración - bien diferente a la estimulante controversia de otras épocas - que ha costado más de una década empezar a superar.

Quede constancia de algunos ejemplos flagrantes del desbarajuste de estos años. En primer lugar, la actuación en un monumento de primerísimo orden, el mo. nasterio riojano de Santa Maria de Nájera, cuya riquísima historia y su magnifica pero castigada arquitectura exigian una intervención urgente, y el escaso presupuesto público disponible se malbarató en una incontrolada e innecesaria obra de diseño realizada en contra de la voluntad de los depositarios de aquel patrimonio de todos.

Mientras los edificios de auténtico rango monumental sufrian a menudo tales dislates, viejos inmuebles que en condiciones normales hubieran tenido un ocaso sereno, o una muerte digna, fueron ridiculizados utilizando en vano el nombre de la restauración. Sirva como modelo de esas abrumadoras intervenciones sobre patrimonios de segundo orden (que por su endeblez monumental aún aceptan menos las alegrias de los diseñadores) el caso del ex convento de Santa Mónica en la rambla de Barcelona.

No se trata de denunciar por denunciar, sino para ayudar a la reflexión respecto de qué actitudes debemos abandonar para aligerar la ya de por si pesada mochila que lleva a sus espaldas la restauración en su caminar hacia el siglo XXI. En este sentido, no quisiera dejarme en el tintero otras actitudes hijas del desbarajuste que ha tenido unos frutos y unas secuelas que van a ser difíciles de olvidar en mi ciudad, Barcelona, la ciudad más de las paradojas que de los prodigios, que si bien ha dado una lección al mundo del consumo reutilizando el viejo estadio olimpico de Montjuïc, mientras - de la mano del terrible e implacable urbanista Cobiha castigado más que nunca su patrimonio. (¿Cómo olvidar la salvaje destrucción de los restos de la antigua Ciudadela, preservados en el subsuelo desde hacia un siglo y eliminados sin compasión un dia de septiem. bre de 1989?).

Actitudes denunciables como el "fachadismo", la comparación de la restauración con la cosmética o la que ha sido bautizada como "sodomía monumental" (11), como la de ese edificio que abraza por detrás a un desvalido edificio modernista de Josep Puig i Cadafalch de la calle Còrsega de Barcelona, violado en plena via pública y a la luz del dia, han creado un estado de opinión pública de alto riesgo para el patrimonio.

En la clave de este desbarajuste, a parte de estas circunstancias profesionales, culturales y políticas, hay que saber ver, una vez más, la influencia de la descompensación entre las valoraciones de los componentes documental y arquitectónico del monumento. Si durante los años del letargo español fue la inoperante visión 
falsamente documental la que predominaba, durante el desbarajuste, un vaivén pendular habia de propiciar una infravaloración -incluso la total ignorancia- de los aspectos documentales, haciendo que muchas de las actuaciones que benévolamente fueron catalogadas como "armonización de la obra antigua con elementos nuevos sin originar ambigüedades arqueológicas" (12), no fueran más que transformaciones traumá. ticas irreparables, o ejercicios gratuitos de diseño virtuosista.

Cierto que mientras el desbarajuste ocultaba a los profesionales jóvenes, a los ciudadanos y a sus deslum. brados administradores, la esencia (diversa, discutible, pero no subvertible hasta ese punto) de la restauración, se incubaba una nueva concepción entre quienes es. tán convencidos de que habia que volver a escuchar los mensajes ocultos de los viejos maestros y, sobre todo, a tener presentes simultáneamente los dos conceptos (documental y arquitectónico) del monumento. En este empeño por regenerar el concepto de restauración, que incluye la recuperación del vocablo, suplantado por las más diversas palabrejas, están las claves de la nueva restauración del inicio del tercer milenio.

\section{La autenticidad del monumento}

Llegados a este punto y antes de formular los caminos deseados para la restauración en el siglo XXI, per. mitidme profundizar - a partir de esa lectura de la historia- algunas reflexiones sobre sus objetivos y sus medios, y en primer lugar sobre la esencia y la autenticidad del propio objeto de la disciplina, el monumento.

Acotar los rasgos esenciales del monumento, definir en qué consiste su autenticidad, es fundamental para plantear correctamente su restauración. Porque cuando la benemérita Carta de Venecia de 1964 (el más res. petable de los manifiestos modernos sobre cómo actuar en los monumentos) nos reclamaba la necesidad de transmitirlos a las generaciones futuras "con toda la riqueza de su autenticidad" (13), ¿a qué autenticidad se referia? ¿a la de la materia que a nosotros nos llega; o a la de la significación de esos monumentos, de las emociones que han producido a las generaciones anteriores y las que aún pueden producir a la nuestra y las venideras? ¿Cuál es, en definitiva, la esencia del monumento, su materia o su mensaje? ¿Cuál será, por tanto, el objetivo de la restauración, transmitir la materia o transmitir el mensaje?

Y en cuanto a la materia, teniendo en cuenta que un monumento es fundamentalmente arquitectura ¿qué es lo esencial, el material, el trabajo realizado en él, la fecha en que se hizo ese trabajo, el espacio que conforma ese material, el ambiente que se respiraba en ese espacio? ¿En qué consiste la autenticidad, en el hecho de que, forma, espacio y ambiente estén conformados

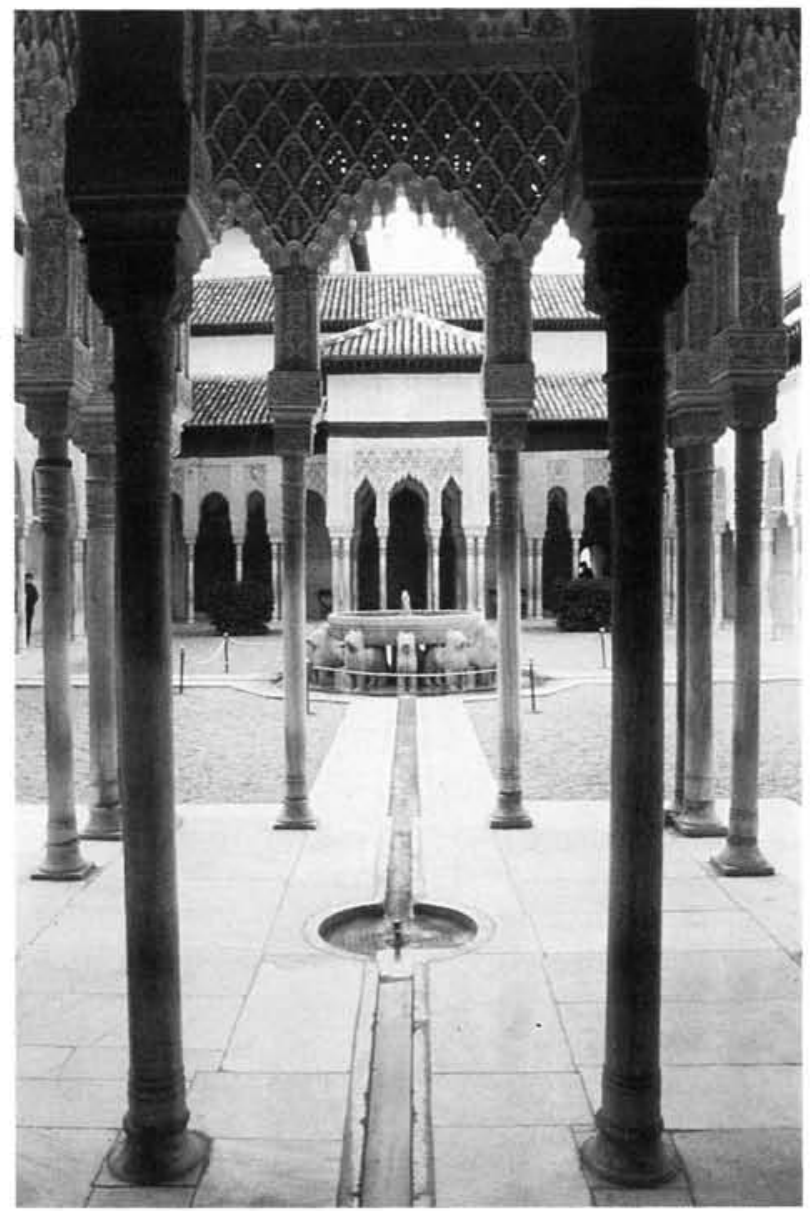

10.- El patio de los leones de la Alhambra: la permanencia de la autenticidad del monumento. (Foto: Arxiu GMN).

por el mismo material que los conformó la primera vez?; ¿o en que respondan a la idea, al proyecto, a la creatividad primigenia aunque el material sea el mismo pero nuevo?

Siempre me ha parecido un agravio comparativo con la arquitectura la valoración que hacemos, por ejemplo, de la orfebrería histórica. Ante una rica custodia cuajada de piedras preciosas nadie duda de su autenticidad por el hecho de que esas piedras no sean las originales: si los avatares de la historia han obligado a reponerlas, sólo se requiere que sean tan preciosas como las originales (protestariamos, eso sí, si fueran reproducciones de materiales ordinarios) y que respondan al plan previsto por el orfebre que concibió la obra. Ahi está la cruz de la Victoria de la cámara santa de Oviedo, destruida, expoliada y rehecha que hoy aún estremece por su mensaje de antigüedad y de belleza. ¿Por qué nadie duda de su autenticidad y si de la de la propia cámara santa, también reconstruida después de la salvaje destrucción de 1934?

Recuerdo que respondi interiormente a algunas de las preguntas sobre la autenticidad de los monumentos paseando por el patio de los leones de la Alhambra. Aun- 


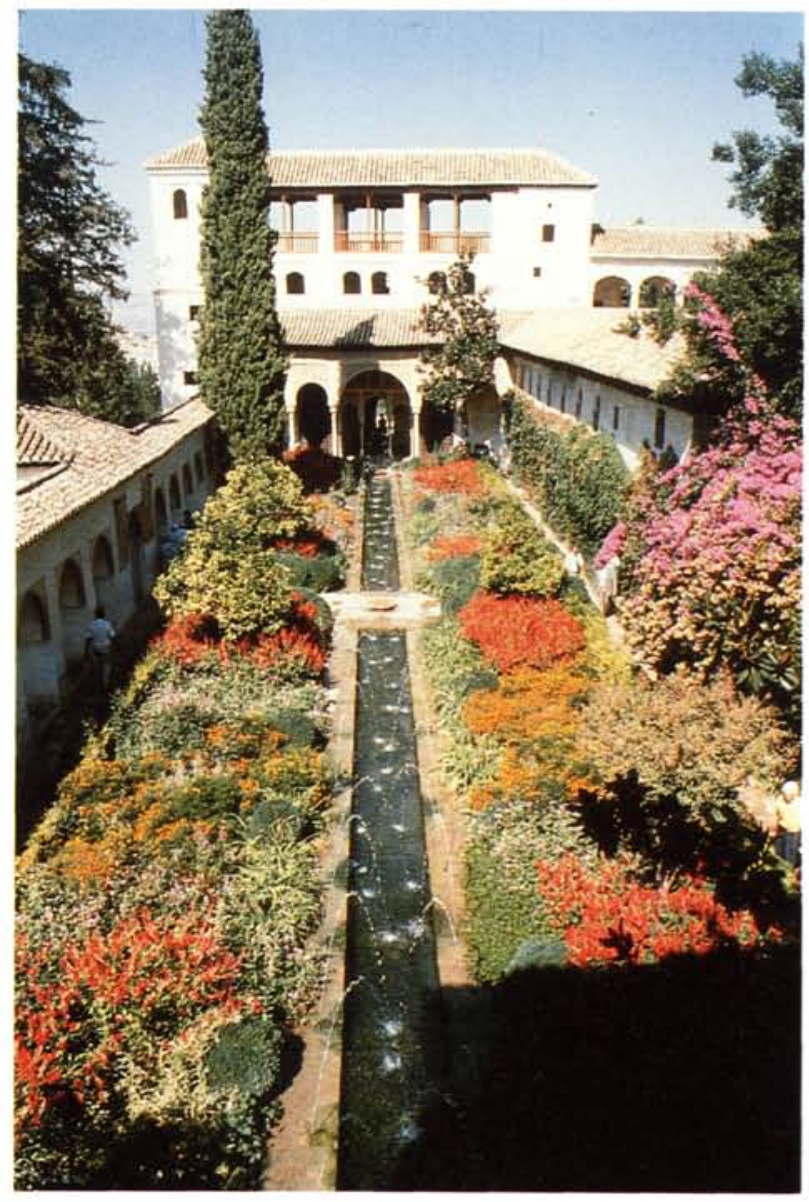

11.- El jardin del Generalife de Granada. (Foto: Arxiu GMN).

que ninguno de los pavimentos, de los tejados o los revestimientos de los muros, ni de las columnas (que según me informaron son substituidas periódicamente ante la inutilidad de la restauración), aunque ninguno de esos materiales y elementos que vemos hoy en ese maravilloso patio no sean de la época nazarí, nadie podrá decir, pensé, que el patio no sea nazarita. Lo es el espacio, el juego de la luz y de las sombras, el murmullo del agua, la fragancia de las flores; lo es, por lo tanto, la arquitectura; y como mensaje de esa arquitectura nazari - no de los restauradores que ha tenido- es como hoy lo disfrutan los miles de visitantes.

Efectivamente, no es tanto la materia de los monumentos - que se quiera o no, acaba por morir - lo que se traspasa de generación en generación, como las emo. ciones (arquitectónicas, testimoniales, significativas) que producen. Ellas son las que se puede y se deben mantener vivas. A diferencia de lo que ocurre en otras artes, en arquitectura la materia en si es menos impor. tante que la forma, el espacio y el ambiente que genera; forma, espacio y ambiente, cuya conservación o recuperación es más primordial para garantizar la autenticidad del monumento que la de esa materia que, de hecho, puede subtituirse sin que la autenticidad del monumento se resienta.
(¿No ocurre algo parecido en la conservación de los jardines históricos, cuya parte vegetal se renueva continuamente por ley de vida sin que se resienta la belleza ni la autenticidad del conjunto? Todas las flores que embriagaron a los arquitectos nazaries que habitaron el Generalife murieron, como morirán las que fotografian cada dia miles de turistas. Pero para que nosotros podamos sentir lo que sintieron los nazaritas, para que nuestros descendientes puedan sentir lo que hoy sentimos, nadie piensa en conservar esas flores muertas, bastará con reponerlas por otras vivas que tengan su mismo color, su mismo olor).

La diferencia del monumento, en cuanto a documento histórico, con otras creaciones artísticas del pasado, condicionará sin duda el modo de plantear su conservación en aras a transmitir su autenticidad. La recuperación de un espacio perdido puede formar parte de la estricta conservación documental de una arquitectura histórica, aunque suponga la aportación de materia no auténtica en el sentido de no trabajada en el mo. mento inicial. Transmitir la autenticidad del Partenon a las generaciones futuras, por ejemplo, habría de presuponer reconstruir suficientemente su fábrica como para que volviese a delimitar un espacio arquitectónico. Ciertamente, consolidar únicamente los restos esparcidos por la Acrópolis es conservar unos "despojos arquitectónicos" griegos, pero no una "arquitectura" griega, cuya autenticidad no se puede concebir sin ese espacio, elemento esencial de la arquitectura.

\section{Fines y medios de la restauración}

Definir los medios válidos para la restauración exige antes, como en cualquier actividad planteada con racionalidad, determinar los objetivos. Es evidente que en función de la doble consideración documental y arquitectónica del monumento, cabe considerar como objetivos genéricos de toda restauración - que han de condicionar y matizar los demás y, evidentemente, la metodología a emplear - la conservación del monumento-documento (o mejor, de la información que el monumento proporciona) y la conservación del objeto arquitectónico (o mejor, la de sus valores formales, de uso y de significación colectiva).

Tanto en uno como en otro caso, no debe entenderse sin embargo la palabra conservación como sinónima de preservación - un error demasiado habitual-, sino de permanencia. En el caso de la conservación de los valores informativos del monumento, como en el de los aspectos conmemorativos, a menudo será más importante la conservación (permanencia) del testimonio que la conservación (preservación) de las estructuras físicas que han permitido su conocimiento.

http://informesdelaconstruccion.revistas.csic.es 


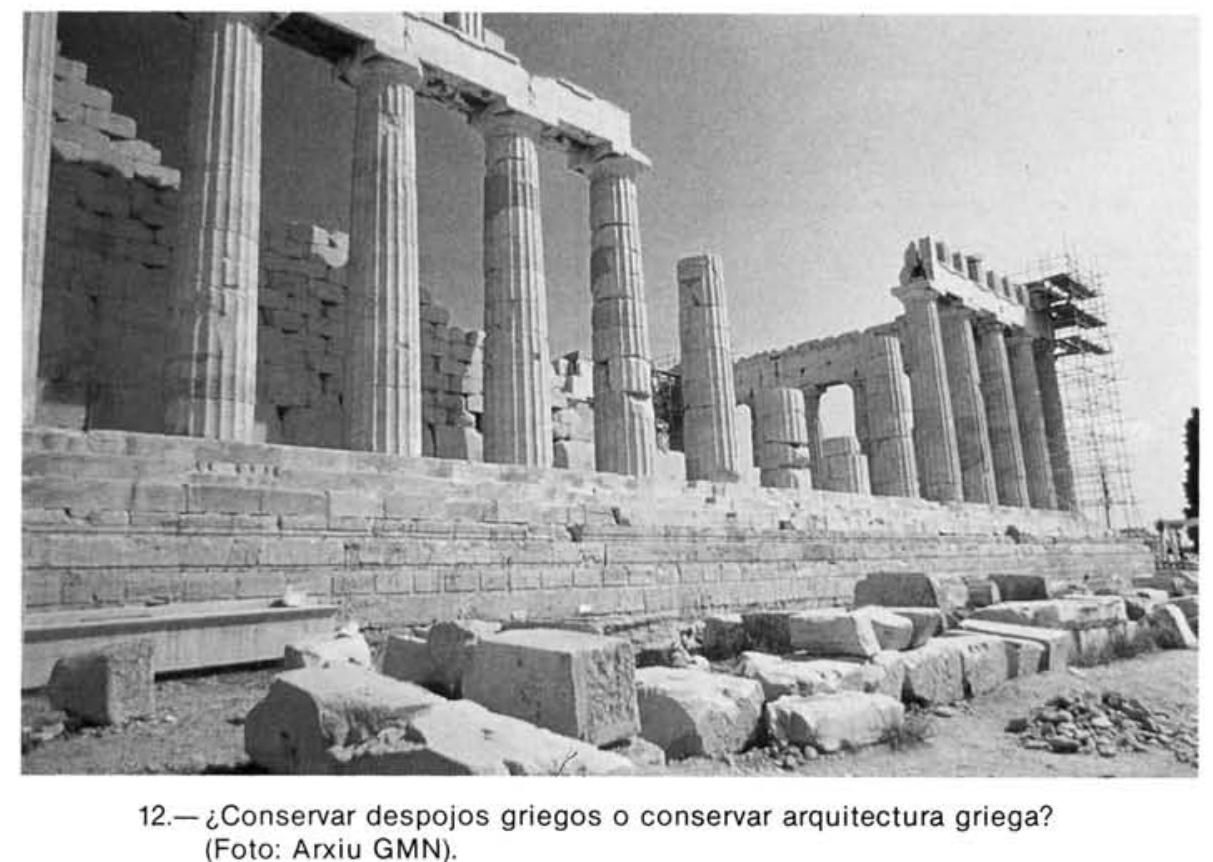

Sabido es que en cuanto al valor informativo, se trata de asegurar la extracción científica de toda la información que el monumento pueda suministrar, algo especialmente importante en aquellos monumentos que por su cronología o circunstancias, nos pueden facilitar información muy difícil o imposible de obtener mediante la documentación escrita y menos aún la llamada "historia oral". Es evidente que en este caso la conservación de los elementos físicos que son soporte de esa información será siempre hasta dónde sea posible, ya que paradójicamente, para "conservar" esta información casi siempre hay que "alterar" el monumento: recordemos que la excavación arqueológica - pieza clave de esa investigación histórica- obliga a destruir los sucesivos estratos que son estudiados, "como si la lectura de un libro obligara a destruir una página antes de leer la siguiente", y que la utilización sistemática de técnicas de conocimiento no destructivas, por su elevado costo y dudosa eficacia, es impensable en la mayor parte de las actuaciones.

La conservación (la permanencia) del carácter de creación artistica del monumento - otro de sus aspectos documentales-, no tiene mucho que ver con la conservación (preservación) de la Obra de Arte en general. La visión del monumento como una creación artistica acabada y no modificable (como ocurre con un cuadro o una escultura, los cuales una vez desaparecido el autor, ya nadie puede modificar, como máximo limpiar), es uno de los errores habituales de quienes juzgan la restauración de monumentos sin atender las pecualiaridades que hacen el patrimonio arquitectónico tan diferente de otros patrimonios y sin tener en cuenta los objetivos de su restauración que hacen de esta disciplina en muy poco comparable con otras aparentemente similares.

La condición más habitual del monumento, la de arquitectura viva que ha de usarse, obliga a considerar en la mayoria de los casos el monumento como una "obra permanentemente inacabada" en la que debe interve nirse, que debe ser modificada.

Junto a los objetivos derivados de la valoración histórica y artística del edificio, hay que tener en cuenta los relacionados con los valores y problemas especificamente arquitectónicos, y entre éstos es primordial la capacidad del monumento de admitir nuevos usos cuando se pierde el primitivo.

Según Viollet le Duc, referencia obligada en tantos as. pectos de la restauración, el arquitecto "tiene la posi. bilidad de conciliar el papel de restaurador con el de artista encargado de satisfacer necesidades no previsibles", ya que "el mejor modo de conservar un edifi. cio es encontrarle un destino, y satisfacer de tal manera las exigencias del mismo - añadia lleno de cautela y de utopia-, que no haya motivo alguno para otro cambio". 


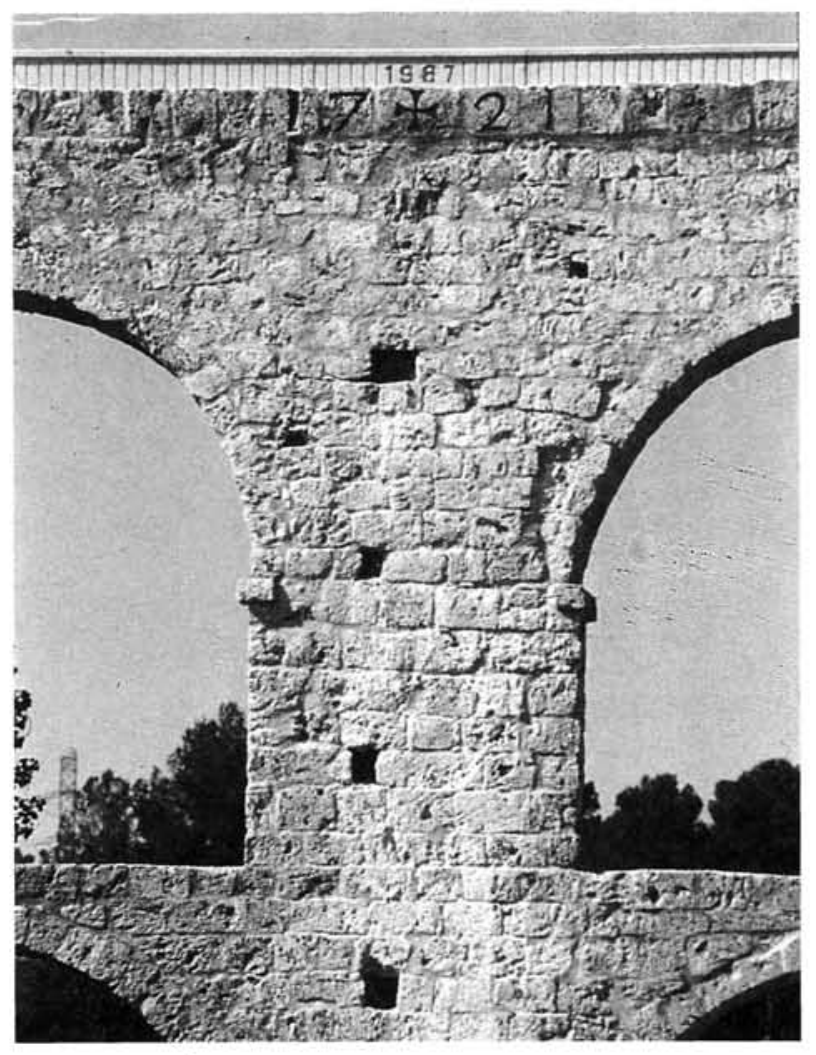

13.- La pervivencia del uso a través de la historia. Acueducto de Sant Pere de Riudebitlles (Barcelona). Restaura. ción de Antoni González. (Foto: Arxiu GMN).

"El vino nuevo fermenta mejor entre maderas viejas" -decia nuestro Jeroni Martorell, auspiciando la reuti. lización de viejos edificios para nuevas funciones, un sistema eficaz para la protección monumental recono. cido por la propia Carta de Venecia, que apostillaba con temor justificado que esta dedicación deseable, "no puede ni debe alterar la disposición o el decoro de los edificios" (14).

La conveniencia del nuevo uso debe analizarse, efectivamente, desde la óptica de la adecuación tipológica, pero también de su capacidad de servir para mantener vivo el monumento que es el objetivo principal. Tan rechazables son las propuestas de reutilizaciones absurdas, decididas sin una reflexión sobre la capacidad real del monumento de asumir su transformación, como las teorías que preconizan el mantenimiento de la arquitectura histórica sin uso, por considerarlo siempre co. mo causa de degradación o de alteración del mensaje primitivo.

\section{Restauración como metodologia}

El ejercicio profesional de estos últimos años nos ha llevado a definir un método (15) en el que de acuerdo con la esencia del monumento, tienen un papel deci- sivo, tanto la lectura previa (histórica, arquitectónica, significativa) del monumento, como el diseño arquitectónico en la resolución de los problemas de re-significación y de uso que su conservación plantea (16). Permitidme ahora algunas reflexiones sobre esos dos aspectos del método.

En cuanto a la lectura previa, una reflexión imprescindible de cara a ese futuro que se nos viene encima, es la prevención (que no supone necesariamente desconfianza) respecto de las complejas tecnologias anaíticas y terapéuticas cada día más en auge. El prestigio que cada dia alcanzan en nuestra cultura tecnificada las cuanto más mejor sofisticadas e incomprensibles tecnologías, unido a la veleidad o irresponsabilidad de algunos arquitectos poco informados puede llegar a hacer creer que su uso es imprescindible, incluso llegar a convertirse en uno de los objetivos de la Restauración.

El alto costo de estas tecnologías analíticas, especialmente teniendo en cuenta los recursos disponibles, nos obliga a ser extremadamente prudentes en su uso y a utilizarlas sólo cuando nos conste que pueden ayudar eficazmente -en palabras del ingeniero italiano Giorgio Croci, apostol desde su cátedra de la universidad romana de la Sapienza de este tipo de estudios-, "a plantear la minima intervención posible con la seguridad de que es suficiente para conservar el monu. mento" (17).

En cuanto a las tecnologias terapéuticas, advertir que el desarrollo y difusión de modernas técnicas de consolidación, limpieza o tratamiento de materiales y estructuras - que tanto deslumbran a los profanos, y que pueden llegar a hacernos creer que son el auténtico futuro de la restauración-, conlleva el riesgo de decidir su uso sin reflexionar suficientemente si son necesarias o no. Es decir, de aplicarlas por el hecho de tenerlas a nuestro alcance, no por precisarlas en función de unos objetivos previamente definidos, olvidando que son más que medios que nunca podrán substituir a la reflexión conceptual. El disponer de eficaces máquinas o potentes productos para limpiar las piedras ennegrecidas de nuestros monumentos no podrá substi. tuir nunca, por ejemplo, la reflexión casi filosófica so. bre si es mejor o no mantener las pátinas.

(Y tratando de tecnologias, queria aprovechar el hecho de estar en este instituto para confesaros un secreto. En el curso de la restauración del Palau Güell de Gau. di, patrimonio de la Humanidad como sabéis, debimos enfrentarnos hace poco a un problema arduo: la lim. pieza de la fachada de piedra calcárea de Garraf. Recorrimos el amplio espectro de ofertas tecnológicas que hoy ofrece el mercado de la restauración, pedimos pruebas a los más variopintos vendedores de ilusiones y por fin dimos con el producto eficaz: un limpiavajihttp://informesdelaconstruccion.revistas.csic.es 
llas cuyo nombre permitidme que calle, pero que os aseguro que ha sido la solución. Brillantes resultados, como dice la etiqueta del envase.

Lo que sí constituye una de las conquistas de la cultura finisecular de la restauración es la necesaria colaboración interprofesional para decidir el futuro de nuestros monumentos. Después de tantos años de disputas y forcejeos inútiles entre profesionales de la arquitectura y de la historia, hoy somos ya plenamente conscientes que esa responsabilidad ya no puede sino de todos en equipo.

El análisis del monumento, es decir, la definición de los valores (arquitectónicos, documentales, informativos, testimoniales y significativos) que hacen que el monumento sea eso, un monumento, o la definición de los objetivos y los medios de cada actuación, no es cosa ya de uno u otro profesional, sino de un equipo pluridisciplinar en el que cada profesional actúa con sus propias metodologias.

Los trabajos de cada disciplina continuarán correspondiendo a los profesionales respectivos (nada ha de diseñar el historiador, ni debe el diseñador aventurarse a hacer historia), pero es en el contexto de esta cola-

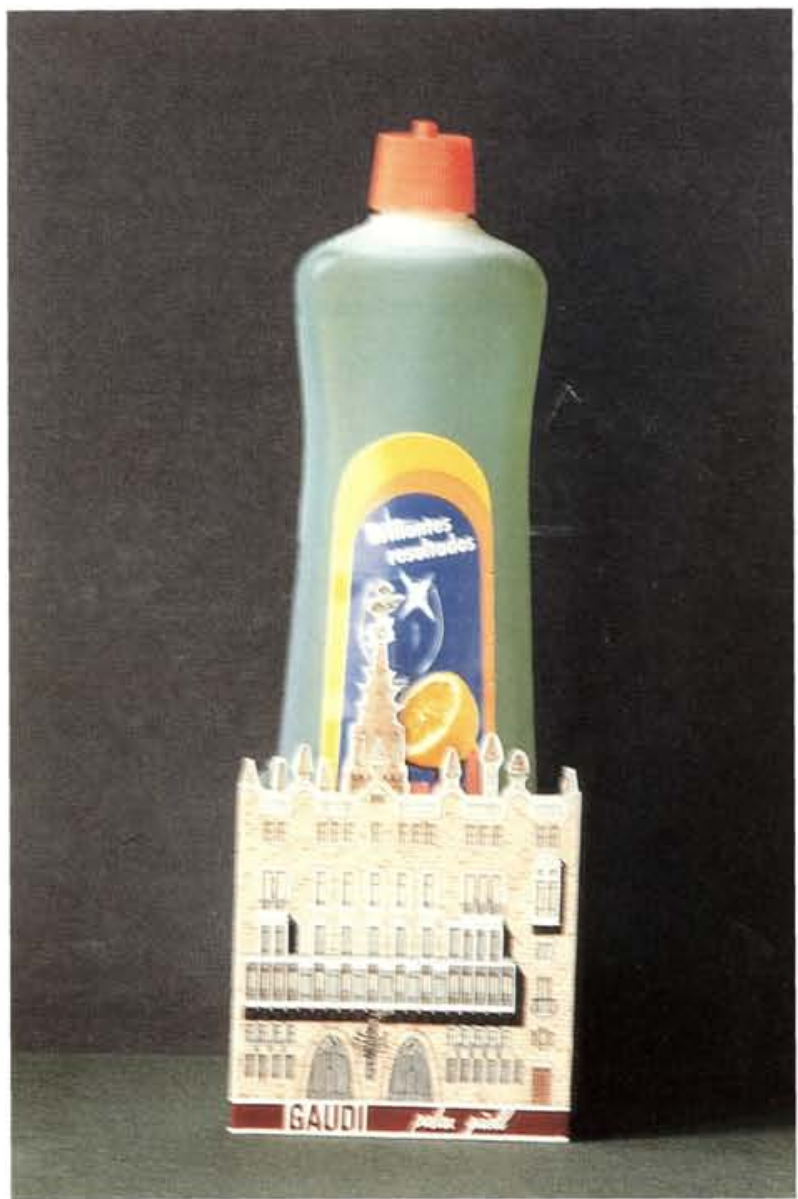

14.- Brillantes resultados en la limpieza del patrimonio. Paradojas de una civilización tecnologizada. (Foto: Arxiu GMN).

(C) Consejo Superior de Investigaciones Científicas

Licencia Creative Commons 3.0 España (by-nc) boración y del respeto mutuo que adquiren pleno sentido y eficacia esos trabajos y deben consensuarse las propuestas.

Sólo en el contexto de un proceso metodológico riguroso, que contemple y respete simultáneamente las dos vertientes fundamentales del Monumento: la documental y la arquitectónica, con los correspondientes objetivos científicos y sociales, es aceptable que el arquitecto plantee el proyecto de restauración monumental con la irrenunciable libertad creativa que conlleva siem. pre el diseño de la arquitectura, tanto cuando sea suficiente prever los escuetos mecanismos de conserva. ción de la fábrica, como cuando -en función de los objetivos- sea conveniente añadir nueva arquitectura a la preexistente. Como dice Salvador Pérez Arroyo, en frase que subscribo con gusto, "utilizar el edificio existente como soporte de nuevas arquitecturas (só. lo) es posible en la medida que se sepa integrar lo propuesto, con el tratamiento adecuado de la información que el edificio posee" (18).

En el siglo XXI, como en este final de siglo que vivimos y como ocurrió siempre desde el siglo XVIII, va a ser la valoración relativa de la doble condición del monumento, como documento histórico y como obje. to arquitectónico, el parámetro decisivo para redefinir la restauración.

Pero de ahora en adelante no se va a plantear tanto en términos de ideología como de metodologia. La definición de una correcta metodologia para la restaura. ción (la mejor herencia que el siglo XXI podrá recibir del $X X)$ ha de partir del adecuado planteamiento de sus fines y sus medios, contemplando siempre conjuntamente esa doble condición del monumento, superando asi las insuficiencias de las teorias formuladas a lo largo de dos siglos.

Acabaremos el siglo XX convencidos de que la actuación en la arquitectura histórica ya no podrá basarse en teorias que marginen el componente arquitectónico; pero tampoco podrá aceptarse ya nunca más el olvido del valor documental del monumento. Iniciaremos un nuevo milenio planteando, por tanto, una disciplina globalizadora, cientifica y creativa al mismo tiempo (más cientifica, pero menos dogmática; más creativa, pero menos veleidosa). Una disciplina, que considere conjuntamente los valores informativos, conmemorativos, formales, de significación y de uso del monumen. to; que plantee las actuaciones con realismo después del análisis objetivo y pragmático de los recursos y de los problemas ciertos de edificios y conjuntos; que atienda las legitimas expectativas de los usuarios y que se desarrolle en un marco de colaboración interprofesional y de diálogo entre todos quienes intervienen en el proceso (promotores, propietarios, destinatarios, pro. fesionales, técnicos y científicos). Asi debería ser, a mi juicio, la restauración de monumentos en el siglo XXI. 


\section{NOTAS}

(1) El Pais. Madrid, 10 de marzo de 1991.

(2) Capitel, Antón. Metamorfosis de monumentos y teorias de la restauración. Alianza Editorial. Madrid, 1988.

(3) González, Antoni. Recercai disseny. El monument com a document históric i com a objecte arquitectónic viu. Investigación y diseño. Research and Design. Ed. Diputació de Barcelona. Barcelona, 1985.

(4) Brandi, Cesare. La inserzione del nuovo nel vecchio. Struttura e architettura. Turín, 1967.

(5) Ruskin, Jhon. Las siete lámparas de la arquitectura. Ed. Alta Fulla. Barcelona, 1987. Pág. 227.

(6) Brandi, Cesare. Teoria del Restauro. Giulio Einaudi, Editori. Turin, 1963.

(7) Recogido en: Bergós Massó, Joan. Gaudi, l'home i l'obra. Editorial Aymà. Barcelona, 1953.

(8) Gaudí utiliza aquí el término arqueología, no refiriéndose a la ciencia que estudia la historia a partir del análisis de los restos materiales, sino como sinónimo de arqueologismo, la expresión de empleo muy común, que de una manera genérica e imprecisa identifica la restauración de monumentos con la imitación acrítica de los estilos antiguos.

(9) Vid. Bergós Massó, Joan. Op. citada.

(10) Vid. Martorell, Jeroni. El Patrimonio artistico nacional. (Conferencia en el Ateneo de Madrid, por Jerónimo Martorell). Arquitectura (órgano oficial de la Sociedad Central de Arquitectos n. 14. Madrid, junio de 1919).

(11) Grassot, Lluis de Sodomia arquitectònica. DIARI DE BARCELONA. Barcelona, 2 de febrero de 1989.

(12) Capitel, Antón. Op. citada.
(13) Texto introductorio de la Carta Internacional sobre la Conservación y la Restauración de los Monumentos y los Sitios Histórico-Artisticos. (Carta de Venecia). Consejo Internacional de los Monumentos y los Sitios HistóricoArtísticos. II Congreso Internacional de Arquitectos y Técnicos de Monumentos Históricos; Venecia, 25 al 31 de mayo de 1964

(14) Carta de Venecia. Art. 5.

(15) González, Antoni. Restaurar monumentos, una metodo. logía específica. INFORMES DE LA CONSTRUCCIÓN N. 397. Madrid, octubre de 1988. Vid. también: FRAGMENTOS, n. 6. Madrid, noviembre de 1985. Arquitectura y Urbanismo en las ciudades históricas. UIMP-MOPU; Madrid, 1988; y Monumento y Proyecto. Ministerio de Cultura; Madrid, 1990.

(16) En cuanto al papel de la investigación histórica: López Mullor, Alberto. "Siete años de investigación arqueológica del patrimonio arquitectónico". En el libro "Com i per a qui restaurem. Objectius, Mètodes i dufusió de la restauració monumental. Memória 1985-1989". Diputació de Barcelona. Barcelona, diciembre de 1990. Vid. tam. bién, González, Antoni. La recerca històrica en el procès d'intervenció en els monuments. MEMÓRIA 1984 Servei de Monuments. Diputació de Barcelona. Barcelona, diciembre de 1986.

(17) Larrauri, Eva. La cúpula electrónica. Las nuevas técni. cas mejoran las restauraciones arquitectónicas. EL PAIS. Madrid, 11.05.1991.

(18) Pérez Arroyo, Salvador; Susana Mora. Proyecto de restauración del Monasterio de Carracedo. Diputación Provincial de León. León, 1987.

(19) González, Antoni. "A la recerca de la Restauració Objectiva". En el libro "Com i per a qui restauren. Objectius, Mètodes i difusió de la restauració monumental. Memòria 1985-1989'. Diputació de Barcelona. Barcelona, diciembre de 1990 . 